\title{
Relationship of Foreign Language Proficiency to Study Abroad Outcomes and Inputs
}

\section{Victor Savicki}

\section{Western Oregon University}

Foreign language proficiency and learning are crucial parts of many study abroad programs; especially those whose host culture language is different than that of the native language of students electing to study in them. Indeed, how a program organizes itself regarding pre-departure language proficiency requirements, on site language learning, and access to academic coursework in the host culture language may impact the intensity of student immersion and the overall quality of the program (Engle \& Engle, 2003). However, there is some debate about the actual impact of foreign language proficiency on student intercultural competence (Deardoff, 2008; Norris \& Steinberg, 2008). Although experts in the study abroad field could not agree on the necessity of foreign language knowledge as a prerequisite for intercultural competence, they did agree on the value of "sociolinguistic awareness-of how one uses language within a societal and social context” (Deardoff, 2008 p38). This distinction seems to differentiate between structural and functional language proficiency. A longitudinal study of U.S. study abroad students showed little or no difference in intercultural measures between students in English speaking programs and those in foreign language speaking programs. Norris and Steinberg (2008) suggest that these findings indicate "the consistent impact of studying abroad, regardless of the program's language of instruction" (p. 120). Even though we might expect foreign language proficiency to have an effect on intercultural competence and other study abroad outcomes, the research findings are uncertain. Part of the inconsistency between expectation and research findings with regard to the impact of language proficiency may lie in the different methodologies of language proficiency assessment. The current study seeks to address two related issues. The first is to examine the relationship between three different measures of language proficiency. The second is to discover the relationship between these measures and study abroad outcomes and inputs. Different measures of language proficiency may be useful for different purposes, and the potential predictive connection to outcomes and inputs may be instructive in designing and implementing study abroad programs. 


\section{Language proficiency assessment}

Language proficiency assessment varies from specific to general, formal to informal, quantitative to qualitative. The least refined, yet most easily attainable measure of language proficiency relies on a count of hours of language coursework students have completed. For many study abroad programs, admission to the program requires that students have completed a minimum number of years of high school, or semesters of college level language. This is common, but quite inexact measure of proficiency since different courses may be more or less comprehensive in their coverage, students may have done more or less well in their academic performance, and the time between completion of coursework and actual study abroad may vary. A somewhat related measure relies on reporting of the number of academic courses students take during their study abroad that are taught in the host culture language (Norris \& Steinberg, 2008). Counting courses is an easy metric to gather and it has a reasonable expectation of relationship to language usage in the study abroad setting.

More formal and quantitative measures of language proficiency focus on written and/or oral language knowledge. In the U.S. the TOEFL (Test of English as a Foreign Language) is commonly used (ETS, 1999). In other countries, similar standardized assessments exist (Engle \& Engle, 2004). These measures have the benefit of normative comparisons and systematic psychometric attention to reliability and validity. They are, however, quite fixed and proscribed in their administration and interpretation.

Language placement tests are at different level of formality and are often given by language faculty at the study abroad site to determine in which language coursework a given student might best enroll. These assessments tend to be less formal, and more focused on the specific milieu of the study abroad program. They suffer from lack of comparison to foreign language speakers generally, but often better assess language usage as it may be expressed in the program's specific milieu.

At the extreme informal end of the assessment spectrum, language faculty may engage students in conversations (structured and unstructured) or use locally prepared vignettes to identify language level and sensitivity to both verbal and nonverbal aspects of communication (Wagner, 2008). Such assessments benefit from the intense, personal attention of the faculty, but usually exert heavy demands on time and professional judgment, which may be influenced by subjective rather than objective factors.

Finally, with regard to actual language usage in a study abroad setting, student self-report may offer an uncomplicated yet reasonably accurate 
measure of how students actually employ the host culture language during their sojourn. Laroche, Pons, and Richard (2009) suggest a three factor model for assessing student language usage in specific contexts (family, media, consumption, shopping). Although fraught with the limitations of self-report, this approach seems to be a realistic method to tap actual language usage, short of independent observation, which has its own limitations.

In summary, several methods of assessment of language proficiency have been used in the service of measuring students' strengths and weaknesses. Each has advantages and disadvantages. We presume that they are overlapping, yet unique measures; each tapping some aspects of language proficiency, yet non comprehensive enough to provide the whole picture.

\section{Study abroad outcomes}

Study abroad affects students on many different levels. Ward (2001) offers a scheme to understand the integrated processes involved in acculturation to a study abroad culture that taps several aspects of human experience. She describes three general categories in which study abroad sojourners in a foreign culture may react: the ABC's of acculturation. The first, Affect (A), is most related to stress, coping, and psychological well-being. Using the theoretical model of Lazarus and his colleagues, researchers can examine the person-environment interaction inherent in stress and coping (Lazarus \& Folkman, 1984; Lazarus \& Smith, 1988). Key to this approach to stress and coping is cognitive appraisal of both the environmental stressor and the individual's resources to cope with the stressor. In the face of an identical stressor different individuals may react different depending on how they appraise it. Some may see the stressor, coupled with their adequate coping resources, as a challenge that mobilizes them to higher levels of performance and resulting higher levels of self-satisfaction and self-esteem. Others might see the stressor, coupled with their potentially inadequate coping resources as a threat which has the potential to overwhelm them thus evoking anxiety and fear. Still others might see the stressor coupled with depleted coping resources as producing harm and loss with subsequent feelings of depression and grief (Lazarus, 1999). From this theoretical point of view, clearly the manner in which one appraises environmental events has affective consequences.

Study abroad students may suffer psychological distress in the form of anxiety, depression, hostility, and somatic disorders. Others may experience enhanced well-being and satisfaction with life (Diener, Emmons, Larsen, \& Griffen, 1985). These two expressions of psychological well-being, though inversely related, seem to tap somewhat different expressions of well-being or its absence. 
Behavior (B), as the second component of the ABC's of behavior, focuses primarily on those overt actions and skills that may indicate that a study abroad student is "fitting in" with the host culture (Ward \& Kennedy, 1999). Ward (2001) suggests that behavioral adaptation to a new culture follows a social learning approach in which sojourners, such as study abroad students, are faced with learning new skills and behaviors that facilitate their ability to interact. Such learning may require not only developing a culture relevant behavioral repertoire, but also suppressing more habitual, home culture responses. The cultural learning curve is quite steep initially, but seems to level off after about six months in the host culture (Ward \& Kennedy, 1999). In addition to measuring the difficulty of performing culturally appropriate behaviors in various circumstances, the behavioral component may also be relevant to determine how much of a study abroad student's time is spent in direct contact with host culture nationals, thus enhancing their immersion (Savicki, 2010b).

Finally, Cognition (C), the third component of the ABC's focuses specifically on a study abroad student's social identification (Ward, 2001). The emphasis here is on the mental schema the student has regarding his or her national identity, and how that identity may be compared with the assumptions and values of the host culture. Many students, prior to studying abroad, have not had the opportunity to stand aside from the home culture in which they are ensconced. In response to this first head-to-head comparison of cultures they find that they can now articulate aspects of their home culture that had been assumed without examination, and that they come to appreciate their home culture more intensely as a result (Savicki \& Cooley, 2011). Indeed, they may espouse a national identity higher than that of students who did not experience a study abroad sojourn (Savicki, Cooley, \& Donnelly, 2008). Given that most university students studying abroad fall into the late adolescent age category, such identity exposure and exploration coincides with their developmental task of establishing and solidifying a self-identity (Marcia, 1980).

In summary, the ABC's of acculturation forms a framework for examining the outcomes of study abroad from a psychological perspective. Questions remain concerning the relationship of various measures of language proficiency with such outcomes.

\section{Study abroad inputs}

From a psychological standpoint, several aspects of student character and experience prior to their study abroad sojourn may be related to language proficiency. First, prior experience with other cultures might prime students' 
language proficiency. The use of a foreign language in the home, prior experience with foreign travel and/or exchange, and number of friends of different cultural backgrounds might make students more interested in pursuing language competence (Hoff, 2008; Medina-Lopez Portillo, 2004).

Second, some personality variables have been shown to predict study abroad adjustment and adaptation (Savicki, 2010a; Ward, Leong, \& Low, 2004). Extraversion, agreeableness, conscientiousness, and lower neuroticism characteristics seem to function independently of culture specific variations (Ward, Leon, \& Low, 2004). "More outgoing, stress tolerant, persistent students who find it easier to get along culture contact" (Savicki, 2010a). Such characteristics may also be related to language proficiency measures.

Third, measures of potential for intercultural adaptation have been found to predict psychological adjustment (Matsumoto, et al., 2003). An overall readiness for cross-cultural contac, and especially higher abilities in emotional regulation seem to predict study abroad student adjustment over a three month period (Savicki, et al., 2004). These and other readiness factors (Openness, Flexibility, Critical Thinking) may also be related to language proficiency.

Finally, social identification prior to study abroad may make proficiency with a language easier. Less rigid national identity, as a form of social identification, may allow less encumbered access to a foreign language, and to proficiency in it. More thoughtful consideration of national identity may prepare students for accepting foreign ways of thinking and speaking (Savicki, Binger, \& Arrúe, in press). Linkages of these cognitive, social identification variables to study abroad outcomes, however, is mixed (Savicki \& Cooley, 2011).

In summary, several types of experience and psychological variables can be expected to relate to language proficiency by virtue of their relationship to previous intercultural and study abroad research findings.

\section{Hypotheses}

In general, hypotheses for this study focus on the interrelationship between language proficiency measures and their correlations to various study abroad outcome and input variables.

Hypothesis 1. The three measures of language proficiency (coursework completed, initial placement test results, and discretionary language se) will show moderate correlation, yet measure somewhat different aspects of proficiency. 
Hypothesis 2. Language proficiency measures will be related to study abroad outcome variables that span affective, cognitive, and behavioral aspects of acculturation.

Hypothesis 3. Language proficiency measures will be related to study abroad input variables that span prior experience, personality, intercultural potential, and social identity.

\section{Methods}

Participants

Participants were 32 U.S. university students studying abroad for three months in Argentina. The average age was 21.3, 45\% were male, 10\% were Sophomores, 50\% Juniors, and 40\% Seniors. Some fluency in Spanish language was required for admission to the program. On average they had completed 2.5 years of high school Spanish and 1.3 years of university Spanish, though there was a wide range of previous language study. All students participated in four hours per week of both Spanish grammar, and Spanish conversation courses during their sojourn. Academic coursework in both English and Spanish was available during the program.

\section{Measures}

Language proficiency-completed language coursework. High school and university Spanish language coursework were combined to form a composite measure of language coursework completed prior to the study abroad sojourn. Following a formula typical in university foreign language departments, high school leave courses were counted as half that of university courses.

Language proficiency-entry Spanish language fluency. Upon arriving in Argentina, students took a locally constructed Spanish language placement test, and were assigned to one of five different levels based on their test performance. Each student's assigned level (1-5) represents their entry language proficiency.

Language proficiency-discretionary Spanish language usage. At the end of the term students responded to a 6 item language usage questionnaire that employed a constant sum procedure following Laroche, Pons, and Richard (2009). Students estimated the percentage of Spanish and English they used in specific situations; e.g. "read newspapers and magazines," "listen to radio or watch TV," "go traveling," "go shopping." In these situations, use of the host culture language was "discretionary" in the sense that no rules of behavior dictated that a particular language be used as was the case in classroom activities, or while communicating with non-English speaking host families. Cronbach's alpha was .805. 
Positive and Negative Affectivity Schedule (PANAS). Positive and negative mood were assessed with the PANAS; (Watson, Clark, \& Tellegen, 1988). The Positive Activation subscale lists 10 adjectives related to positive mood (e.g. active, alert, attentive). The Negative Activation subscale lists 10 adjectives related to negative mood (e.g. afraid, ashamed, distressed). Participants were asked to rate the extent to which they had felt each of these emotions over the previous three months. Ratings were made on a five point Likert scale, ranging from $1=$ Very slightly or not at all to $5=$ Extremely. Alphas for the current sample were Positive Activation; .852; Negative Activation, .823.

The Appraisal of Life Events (ALE) scale. The ALE (Ferguson, Matthews, \& Cox, 1999) assesses cognitive appraisal of stressful situations via three dimensions: Challenge ( 6 items), the degree to which the environment is perceived as one that allows for personal growth and development through potential mastery of stressors; Threat (6 items), the degree to which the environment is perceived as hostile, apt to generate anxiety, and may be potentially harmful; and Los (4 items), the potential for suffering and sadness. Participants were asked to appraise "my study abroad experience" on 16 adjectives (e.g. stimulating, exciting, fearful, hostile, depressing, painful) using a five point Likert scale ranging from $1=$ Not at all, to $5=$ Very much so. Alphas for the current sample were Challenge, .861; Threat, .817, and Loss, .895 .

Socio-cultural Adaptation Scale (SCAS). In the SCAS Ward and Kennedy (1999) have identified a list of encounters, and issues that may be relevant to sociocultural adjustment. Respondents rate their difficulty in adjusting to cultural situations using a five point Likert scale with $1=$ No difficulty to $5=$ Extreme difficulty. A brief sample of their 29 item scale includes "Making unsatisfactory service," "Getting used to the local food/finding food you enjoy," "Dealing with people in authority," "Understanding the locals' world view" (Ward \& Kennedy, 1999 p. 663). Reliability based on Cronbach's alphas for the current sample was .83. In addition, Ward and Kennedy (1999) factor analyzed their scale and found two factors: Cultural Empathy and Relatedness (13 items, 32\% of variance), and Impersonal Endeavors and Perils (7 items, $9 \%$ of variance).

American Identity Measure (AIM). The AIM (Meyer-Lee \& Evans, 2008) is a social identification scale developed to assess study abroad students' sense of self in terms of their feelings of belonging to and attitudes toward the larger U.S. society. This 10 item scale derives from the work of Phinney and colleagues (Phinney, 1992; Phinney \& Devish-Navarro, 1997). Students responded on a four point Likert scale from $1=$ Strongly Disagree to $4=$ Strongly 
Agree. Two factor analyzed sub-scales assessed the two components of American Identity. Factor 1 (5 items), Commitment/Affirmation (CA), assessed the attachment and personal investment to being an American with items such as Ï have a strong sense of being an American," and "Being an American plays an important part in my life." Factor 2 (5 items), Exploration/Search (ES), assessed the process of seeking information and experiences relevant to defining one's own "American-ness" with items such as "I have spent time trying to find out more about what being American means," and "I have sometimes wondered about the meaning or implications of being American." Alphas for the current sample were CA $=.805, \mathrm{ES}=.819$.

Brief Symptom Inventory (BSI). Psychological well-being/straing was measured based on four sub-scales from the BSI (Derogatis \& Melisaratos, 1983). The five to six item symptom cluster scales included were Somatization: distress arising from perceptions of bodily dysfunction; Depression: dysphoria and lack of motivation and energy; Anxiety: nervousness, panic attacks, apprehension, dread; and Hostility: thoughts, feelings or actions of anger. Coefficient alphas for the sub-scales were Somatization .800, Depression .885, Anxiety .781, Hostility .523.

Satisfaction with Life Scale (SWLS). The SWLS is a five item questionnaire using a seven point Likert scale to rate overall satisfaction with life using questions such as "In most ways my life is close to my ideal" (Diener, Emmons, Larsen, \& Griffin, 1985). The SWLS can be viewed as a measure of psychological adjustment since the scale demonstrated moderately strong criterion validity with several measures of psychological well-being (Diener, Emmons, Larsen, \& Griffin, 1985 pp. 72-73). Alpha for the current sample was .879 .

Personality. Personality was measured using a short version of the Big Five personality factor approach (Fossum, Weyant, Etter \& Feldman-Barrett, 1996). For this 35 item scale, each sub-scale had 7 items. The scales and key defining traits for each include: 1) Neuroticism: anxious, hostile, selfconscious; 2) Extraversion: outgoing, sociable, upbeat, assertive; 3) Openness to experience: curiosity, flexibility, unconventional attitudes; 4) Agreeableness: sympathetic, trusting, cooperative, straightforward; 5) Conscientiousness: diligent, disciplined, well-organized, dependable. Alphas for the sub-scales in this sample as Neuroticism .783, Extraversion .793, Openness .766, Agreeableness .571, Conscientiousness .707.

Intercultural Adjustment Potential Scale (ICAPS). The ICAPS consists of 55 items with responses given on a scale ranging from $1=$ Strongly Disagree to $7=$ Strongly Agree. A total score (ICAPS Total) was computed by summing all items (24 reverse coded) with higher scores indicating greater adjustment 


\section{Victor Savicki}

validity for adjustment to a new culture based on peer and expert interviewer ratings, as well as self and subjective ratings (Matsumoto, et al., 2001 p492). Four factor scores were also derived -Emotion Regulation (ER): the ability to modulate one's emotional reactions to avoid employing psychological defenses, Openness (OP): the ability to engage in learning about the new culture, Flexibility (FL): being free of over-attachment to previous ways of thinking and willingness to tolerate ambiguity, and Critical Thinking (CT): the ability to generate creative, new hypotheses about incidents in the new culture that go beyond one's home cultural framework. All five ICAPS scores were transformed to T-scores with a mean o 550 and standard deviation of 10 based on a normative sample. The authors of the scale reported alphas of .783 for the ICAPS Total, .638 for Emotional Regulation, .601 for Openness, .568 for Flexibility, .433 for Critical Thinking (Matsumoto, et al., 2001).

General Contact levels. Percent of contact with individuals from different cultures was measured by student responses to the following question given at the end of the study abroad term:

When thinking about the last month, please estimate the percent of time you spent in face to face contact with the following kinds of people (the percentages should add to $100 \%$ ). In situations in which you may encounter more than one type of person at once (e.g. host culture teacher in a class with fellow American students), please count that as contact with the host culture.

The response alternatives were 1. American students, 2. People in the host culture (teachers, shop keepers, other students, etc), and 3. People of a different culture (neither home nor host culture).

\section{Procedures}

Students voluntarily responded to a pre-departure questionnaire immediately prior to or upon arrival at their study abroad program. They completed the post program questionnaire during week 11 of the 12 week program. They also completed the SCFAS during weeks 2, 5, and 8 . All data was treated with confidentiality.

\section{Results}

Results for this study will first focus on the relationship between the three measures of language proficiency, then on the relationship of those measures to study abroad outcomes and inputs. Special attention will be given to the moderate mismatch between student perceptions of the importance of various adaptation difficulties and their likelihood of employing the Spanish language to address them.

Relationship of language proficiency measures to each other 
The first three rows of Table 1 show that the language proficiency measures were, as hypothesized (with one exception), moderately, significantly correlated. Number of Completed Language Courses predicted Initial Language Level which predicted Percent of Spanish Used, but the Number of Completed Language Courses did not predict Percent of Spanish Used. The largest correlation, between Initial Language Level and Completed Language Courses, only accounts for $33 \%$ of the variance between variables. The smallest correlation, between actual Percent of Spanish Used and Completed Language Courses, accounted for only $8 \%$ of the variance. To expect that actual language usage can be predicted on the basis of number of completed language courses seems unlikely; for example, a visual examination of the scattergram of Number of Completed Courses by Percent of Spanish used showed several students with low previous coursework who spoke a high percentage of Spanish. Several other factors, e.g. motivation to speak, may be more potent (Paige, et al., 2003). Although the measure were related, they seem to offer differing perspectives on the concept of foreign language proficiency. It remains to be seen which of these measures may be more useful for predicting the development of intercultural adjustment and adaptation.

Relationship of language proficiency measures to study abroad outcomes

In general, measures of language proficiency had a positive relationship with affective aspects of student acculturation. All proficiency measures showed that more proficient students reported significantly less threat appraisal (see table 1). Those actually using higher percentages of Spanish during their study abroad sojourn showed significantly less Negative Affect, Depression and Anxiety (marginal significance). Interestingly, students with higher Initial Language Levels also showed significantly less of the stress appraisal of Challenge. Overall, the measure of Percent of Spanish Used seemed most tightly related to these affective measures with the most significant correlations.

For American Identity, the cognitive, social identification component of study abroad outcomes, Table 1 shows that Percent of Spanish Used significantly correlated with the American Identity Measures Commitment/Affirmation factor. The more students used their foreign language in discretionary situations during their sojourn, the more they expressed approval for and endorsement of their national identity. It may be that using language to immerse themselves in the Argentine culture allowed students a greater opportunity to make cultural comparisons, and thus to acquire a greater appreciation for the uniqueness of the U.S. culture. However, 
the Explore/Search factor of this social identification scale did not relate to any of the language proficiency measures.

On the behavioral level, none of the language proficiency measures was correlated with general measures immersion: the amount of contact that students had either with their U.S. peers, with host culture nationals, or with people from other cultures. In other words, higher proficiency did not relate to higher percentages of interaction with native Spanish speakers; conversely, lower proficiency did not relate to higher percentages of interaction with English speaking peers. Regardless of proficiency, students had similar percentages of contact with peer and host culture groups. Similarly, for overall measures of the behavioral outcome of sociocultural adaptation, none of the language proficiency measures correlated significantly with either the SCAS Total score or either of the factor scores: Cultural Empathy and Relatedness; Impersonal Endeavors and Perils. However, the summed scores of the above scales were masked interesting findings that appeared when individual items of the SCAS were considered. To get a more accurate sense of the importance of the individual items, not only was student reported difficulty with the item noted, but also student reported frequency of occurrence (see table 2). A weighted average (frequency $\mathrm{x}$ difficulty) was calculated to capture the importance of each the 29 SCAS items. This combined index was deemed a more accurate measure of each item's impact on students.

Figure 1 shows a substantial variation in distribution in importance $f$ the 29 items. "Making yourself understood" with a frequency of 4 (Regularly) and a difficulty of 2.485 (Slight to Moderate) ranked highest along with "Getting used to the local food/finding food you enjoy." "Worshipping in your usual way" with a frequency of 1.906 (Seldom) and a difficulty of 1.645 (None to Slight ranked lowest. A few items occurred with some frequency but were rated not at all difficult ("Going to social events/gatherings/functions," "Dealing with the climate"). Other items were rated difficult, yet happened infrequently enough that they did not reach the threshold for importance ("Making friends," "Dealing with someone who is unpleasant/cross/ aggressive"). For the purposes of discussion, those items with weighted scores of plus or minus 1 or more (one standard deviation from the mean) will be highlighted.

Table 2 shows the correlations of the language proficiency measures to the end of term weighted mean z-scores. The Completed Language Courses measures of language proficiency was inversely related to one specific SCAS items: "Taking about yourself with others", and positively related to two others: accepting/Understanding the local political system," "Seeing things from the locals' point of view." To the degree that language courses at U.S. 
high school and universities address the unique cultures of various Spanish speaking countries, coursework is more likely to have a mixed effect on sociocultural adaptation. While more coursework was related to less difficulty in talking about one's self with others, it was related to more difficulty in understanding local politics, and seeing the local point of view. Language coursework in the U.S. may give students a rehearsed, cookbook strategy for initial "getting to know you" conversations, but seemed to obscure understanding of both political and culture specific appreciation for values and perspectives of Argentina. These relationships may indicate a need to reevaluate how U.S. based language courses deal with country-specific information in addition to coursework which may emphasize grammar, syntax, and vocabulary (Paige, et al., 2003; Savicki, Binder, \& Arrúe, in press).

Initial Language Level was correlated with "Going shopping," "Talking about yourself with others," and "Following rules and regulations." All of these adaptations were less difficult if a student entered the study abroad sojourn with a higher level of Spanish language competence. A longitudinal tracking of students by initial language level showed that students with higher initial language proficiency had less difficulty in the early stages of their sojourn $(r=$ $-.486, p<.01$ ), but that their advantage in adaptation disappeared by the middle through the end of their sojourn. Nevertheless, this early adaptation may have had potential benefits throughout their sojourn by affirming an initial sense of mastery in the host culture (Savicki, 2010a). In addition, both "Going shopping" and "Following rules and regulations" were of less importance when both frequency and difficulty were considered (more than 1.0 standard deviation). Students with higher initial proficiency may have felt less threatened by the prospect of fitting in with daily life in Spanish speaking culture, but their proficiency seemed expended mostly in relatively nonchallenging adaptations.

Finally, Percent of Spanish Used related to the most items from the SCAS. Five of these significant correlations occurred with items that were seen as not important, or within an average range (e.g. "Accepting/understanding the local political system," "Relating to the opposite sex," "Making friends.") Although speaking the host culture language in these situations showed proficiency, it did not represent a challenge for fluent speakers. The two challenging situations "Dealing with unsatisfactory service in stores and restaurants," and "Finding your way around" represent situations that happened often enough and posed enough difficulty that students' proficiency was put to the test.

Several of the more important items on the SCAS were not correlated with any of the language proficiency measures; e.g. "Making yourself understood, 
"Understanding jokes and humor," "Getting used to the local food/finding food you enjoy," "Adapting to host family relationships." It may be useful for programs to identify such high importance adaptation issues and address them in the on-site program regardless of student language proficiency.

In summary, language proficiency measures have a differential relationship with study abroad outcome indicators. Especially revealing are the connections between proficiency measures and specific cultural learning tasks. While language proficiency may be related to decreased stress appraisals and decreased distress symptoms, and increased appreciation of national identity, its relationship with behavioral outcomes is somewhat mixed. Students might be better served by focus on important, though often ignored, adaptation issues at the same time as they relish their mastery in less difficult situations.

Relation of language proficiency measures to study abroad inputs

No student demographic experience variables correlated significantly with any of the language proficiency measures. That is, neither weeks of previous foreign travel, number of friends from other ethnic backgrounds, emphasis on ethnicity within the students home family, nor language spoken in the home family was related to language proficiency. The only such variable showing marginal significance $(r=.440, p<.10)$ was the correlation of weeks of previous study abroad to placement test score; and this applied to only three students. In general, none of the usually collected information from student application forms seemed to be related to language proficiency.

Table 1 indicates two seemingly conflicting patterns of psychological inputs to study abroad with measures of language proficiency. First, students with higher Initial Language Levels showed significantly greater Critical Thinking and marginally lower Neuroticism. Both of these relationships bode well for successful study abroad adjustment and adaptation. At the same time, students with higher Initial Language Levels showed lower pre-departure levels for the American Identity Commitment/Affirmation factor. Additionally, higher performers on all language proficiency measures showed lower scores on the Explore/Search factor of the AIM. Simultaneously, students who are cognitively and emotionally ready for new experiences in their study abroad, have also expended less time and energy thinking about their home culture identification, and feel less attached to it. Lower attachment to national identity may make it easier for students to be open to a new culture (Savicki \& Cooley, 2011). However, the consistent lack of exploration of identity related to higher language proficiency may indicate a lack of reflection about and critical thinking focused on home culture issues. Several authors in the field suggest developing an awareness of one's home 
culture as a necessary step in developing a more ethnorelative worldview (Kohls, 1998; Le Brack, 2004). None of the measures of language proficiency were positively related to this reflection and national identity exploration process.

In summary, the relationship of language proficiency measures to study abroad experience and psychological input variables was weak and somewhat mixed. The strongest pattern across all measures indicated students with higher proficiencies showing a decreased tendency for active examination of their national identities.

\section{Discussion and Conclusions}

The three language proficiency measures used in the current study were modestly related, yet seemed to account for different aspects as well. Language proficiency appears complex and not comprehensively measured. Each measure has its advantages and disadvantages. The mixed results with regard to study abroad outcomes and inputs may account for the lack of clarity in findings regarding language proficiency and intercultural competence. The most potent measure in the current study was student self-report of percent of Spanish they used in everyday discretionary situations. This measure had the advantage of being concurrent with the outcome measures; both assessed at the end of the study abroad sojourn. Clearly, there is an advantage for students in using the host culture language in terms of positive study abroad outcomes. Early sociocultural adaptation, higher levels of psychological wellbeing, and higher affirmation of national identity correlated with language proficiency.

However, language proficiency seemed to have no relationship to immersion, in the sense that percentages of contact with both U.S. peers and host nationals were uncorrelated to proficiency. This lack of relationship reflects only the quantity, not the quality of the contacts; nor does it specify what language was spoken during those contacts. Future research shou8ld clarify more detail about such contacts. Students with lower proficiency might be able to maintain higher contacts with host culture nationals through using English rather than the host culture language. Such contacts might provide a means for developing intercultural competence independent of language proficiency.

While language proficiency seemed to be related to an easier, less stressful study abroad experience, it was not clear that this ease in language use was necessarily focused on adaptation issues that were most important from the student point of view. None of the language proficiency measures were related to the two most important sociocultural adaptation issues: "Making yourself 
understood," and "Getting used to the local food/finding food you enjoy." Other, non-language variables may be more useful in dealing with these important, adaptation issues. The first, "being understood" may readjust to students' fluency; always receding as their proficiency propels them into more complex language situations. The second, access to food" probably has not much to do with language, and much more to do with availability of preferred items and flexibility in one's palate. Language proficiency has limitation in its effectiveness in promoting sociocultural adaptation.

Another interesting dynamic is the interplay between functional language and grammatically and syntactically correct language. Students can fall into the "fluency trap" in which students start to lose motivation for further language study when they reach the point that they can communicate reasonably effectively with their host culture family, friends, and acquaintances (G. Alcaniz, personal communication, November 3, 2010). Such a drop in motivation may be seen in a leveling off of achievement on standardized language assessment instruments (Engle \& Engle, 2004). When students reach a "good enough" level of proficiency, the relationship between precisely measured achievement and self-reported percent of usage may become ambiguous, especially in a context in which local dialect and vocabulary might vary from accepted language standards. Achievement and daily usage seem to require different motivators.

Additionally, as Bacon (2002) states, "mere competence in an area such as being fluent in a language is not sufficient to guarantee success" in study abroad settings (p. 645). Rather, a major contributor to growth in intercultural competence and sensitivity may stem from the student's ability to reflect on their experience of being an outsider or out group member (Laubsher, 1994, Savicki \& Cooley, 2011). Language proficiency, to the degree that it aids such awareness and reflection, might enhance students reassessing their social identities, as in the connection between actual language use and increase in appreciation for one's national identity in the current study. Sufficient language competence for this purpose may be only modestly connected to precise grammar and syntax, and more tightly connected to both the quality and quantity of interaction with host nationals, and the willingness to think critically about cultural distinctions that arise from those interactions. Readiness to benefits from such cultural interactions may benefit from appropriate learning and orientation both pre-departure, and on-site (Hoff \& Paige, 2008; Selby, 2008). Certainly the inverse relationship between all measures of language proficiency and students pre-departure exploration of their own national identity suggests needed attention to the issues of awareness and reflection, particularly with reference to students' home 
culture. While language courses may focus on cultural issues of the countries in which the languages are spoken, it might also be useful for those courses to make cultural comparisons with the home culture as well.

The current study suffers from a number of limitations. The most important of which are that the results are based on one sample of study abroad students, and rely solely on correlation for their findings. To repeat the old saw "Correlation is not causation." The relationships can be bi-directional. Nevertheless, the findings raise interesting questions for international educators. Future research might better emphasize control groups and experimental manipulations. Larger samples, and additional measures of language proficiency would also be advantageous.

In conclusion, the relationship between different measures of language proficiency and their connection with study abroad outcomes and inputs in the current study showed some trends and some continued ambiguity. The inconsistencies in language proficiency assessment may lead to different conclusions concerning the relationship between language and intercultural competence. Clarification of the overlap and uniqueness of various measures of language proficiency would help in teasing out their impact on study abroad success. The better the students' language proficiency, the more likely they are to seek further language education and experience (Norris \& Steinberg, 2004). But, further language study is but one of many possible study abroad outcomes, and may not be the most important in the development of intercultural competence. The pairing of language proficiency with the development of intercultural competence has the potential for increasing intercultural sensitivity (Bennett, 1993) and avoiding the emergence of "fluent fools" who speak well but commit endless cultural faux pas, offending their hosts in perfect syntax (Bennett, 2008).

\section{References}

Bacon, S. M. (2002). Learning the rules: Language development and cultural adjustment during study abroad. Foreign Language Annals, 35, 637-646.

Bennett, J. M. (2008). On becoming a global soul: A path to engagement on study abroad. In V. Savicki, (Ed). Developing Intercultural Competence and Transformation: Theory, Research, and Application in International Education. Sterling, VA: Stylus Publishing.

Bennett, M.J. (1993). Towards ethnorelativism: A developmental model of intercultural sensitivity. In M. Paige (Ed.), Education for the intercultural experience (21-71). Yarmouth, ME: Intercultural Press, Inc.

Deardorff, D.K. (2008). Intercultural competence: A definition, model, and implications for education. In V. Savicki, (Ed.). Developing Intercultural 
Competence and Transformation: Theory, Research, and Application in International Education (pp. 32-51). Sterling, VA: Stylus Publishing.

Derogatis, L.R. \& Melisaratos, N. (1983). The brief symptom inventory: An introductory report. Psychological Medicine, 13, 595-605.

Diener, E., Emmons, R.A., Larsen, R.J., \& Griffin, S. (1985). The satisfaction with life scale. Journal of Personality Assessment, 49, 71-75.

Educational Testing Service (ETS). (1999). Test of English as a Foreign Language. Princeton, NJ: Educational Testing Service.

Engle, L. \& Engle, J. (2004). Assessing language acquisition and intercultural sensitivity development in relation to study abroad program design. Frontiers: The Interdisciplinary Journal of Study Abroad, X, 219-236.

Ferguson, E., Matthews, F., \& Cox, T. (1999). The appraisal of life events (ALE) scale: Reliability and validity. British Journal of Health Psychology, 4, 97-116.

Fossum, T.A., Weyant, S.A., ETter, L., Feldman Barrett, L. (1998, May). A short and simple alternative to long personality questionnaires. Presented at the annual meeting of the American Psychological Society, Washington, DC.

Hoff, J.G. (2008). Growth and transformation outcomes in international education. In V. Savicki, (Ed.). Developing Intercultural Competence and Transformation: Theory, Research, and Application in International Education (pp. 53-73). Sterling, VA: Stylus Publishing.

Hoff, J.G. \& Paige, R.M. (2008). A strategies-based approach to culture and language learning in education abroad programming. Frontiers: The Interdisciplinary Journal of Study Abroad, XVII, 89-105.

Kohls, R.L. (1998). The Survival Kit for Overseas Living. Yarmouth, ME: Intercultural Press.

La Brack, B. (2004). What's up with culture? Online cultural training resource for study abroad. Retrieved at http://www2.pacific.edu/sis/culture/ March 6, 2011.

Laroche, M., Pons, F., \& Richard, M. (2009). The role of language in ethnic identity measurement: A multitrait-multimethod approach to construct validation. The Journal of Social Psychology, 149, 513-539.

Laubscher, M.R. (1994). Encounters with difference: Student perceptions of the role of out-of-class experience in education abroad. Westport, CT: Greenwood Press.

Lazarus, R.S. (1999). Stress and emotion: A new synthesis. NY: Springer Publishing.

Lazarus, R.S., \& Folkman, S. (1984). Stress, appraisal, and coping. New York: Springer. 
Lazarus, R.S. \& Smith, C. (1988). Knowledge and appraisal in the cognitionemotion relationships. Cognition and Emotion, 2, 281-300.

Marcia, J. (1980). Identity in adolescence. In J. Addison (ed.). Handbook of adolescent psychology (pp. 159-187). NY: Wiley.

Matsumoto, D., Leroux, J.A., Ratzlaff, C., Tatani, H., Uchida, H., Kim, C., \& Araki, S. (2001). Development and validation of a measure of intercultural adjustment potential in Japanese sojourners: The Intercultural Adjustment Potential Scale (ICAPS). International Journal of Intercultural Relations, 1-28.

Medina-Lopez Portillo, A. (2004). Intercultural learning assessment: The link between program duration and the development of intercultural sensitivity. Frontiers: The Interdisciplinary Journal of Study Abroad, X, 179-199.

Meyer-Lee, E. \& Evans, J. (2008, May). New tools for intercultural outcomes learning assessment in D. Deardorff (Chair) Assessment toolbox for international educators. Symposium presented at the NAFSA Annual Conference, Washington DC.

Norris, E.M. \& Steinberg, M. (2008). Does language matter? The impact of language of instructing on study abroad outcomes. Frontiers: The Interdisciplinary Journal of Study Abroad, XVII, 107-131.

Paige, R.M., Jorstad, H.L., Siaya, L., Klein, F., \& Colby, J. (2003). Culture learning in language education: A review of the literature. In D. L. Language \& R. M. Paige (Eds.) Culture as the Core: Perspectives on Culture in Second Language Learning (pp. 173-236). Greenwich, CT: Information Age Publishing.

Phinney, J.S. (1992). The Multigroup Ethnic Identity Measure: A new scale for use with adolescents and young adults from diverse groups. Journal of Adolescent Research, 7, 156-176.

Phinney, J.S. \& Devich-Navarro, M. (1997). Variations in bicultural identification among African American and Mexican American adolescents. Journal of Research on Adolescence, 7, 3-32.

Savicki, V. (2010a). Implications of early sociocultural adaptation for study abroad students. Frontiers: The Interdisciplinary Journal of Study Abroad XIX, 205-223.

Savicki, V. (2010b). An analysis of the contact types of study abroad students: The peer cohort, the host culture, and the electronic presence of the home culture in relationship to readiness and outcomes. Frontiers: The Interdisciplinary Journal of Study Abroad, XIX, 61-86. 
Savicki, V., Binder, F., \& Arrúe, C. (in press). Language fluency and study abroad adaptation. Frontiers: The Interdisciplinary Journal of Study Abroad.

Savicki, V. \& Cooley, E. (2011). American identity in study abroad students: contrasts and changes. Journal of College Student Development, 52, 339349 .

Savicki, V., Cooley, E., \& Donnelly, R. (2008). Acculturative stress, appraisal, coping and intercultural adjustment. In V. Savicki, (Ed.). Developing Intercultural Competence and Transformation: Theory, Research, and Application in International Education (pp. 173-192). Sterling, VA: Stylus Publishing.

Savicki, V., Downing-Burnette, R., Heller, L., Binder, F., \& Suntinger, W. (2004). Contrasts, changes, and correlates in actual and potential intercultural adjustment. International Journal of Intercultural Relations, 28, 311-329.

Selby, R. (2008). Designing transformation in international education. In V. Savicki, (Ed.). Developing Intercultural Competence and Transformation: Theory, Research, and Application in International Education (pp. 1-10). Sterling, VA: Stylus Publishing.

Wagner, E. (2008). Video listening tests: What are they measuring? Language Assessment Quarterly, 5, 218-243.

Ward, C. (2001). The A, B, Cs of acculturation. In D. Matsumoto (Ed.), Handbook of Culture and Psychology. (pp. 411-446). NY: Oxford University Press.

Ward, C., Leong, C., \& Low, M. (2004). Personality and sojourner adjustment: An exploration of the big five and the cultural fit proposition. Journal of Cross-Cultural Psychology, 35, 137-151.

Ward, C., \& Kennedy, A. (1999). The measurement f sociocultural adaptation. International Journal of Intercultural Relations 23, 659-677.

Watson, D., Clark, L.A., \& Tellegen, A. (1999). Development and validation of brief measures of positive and negative affect: The PANAS scales. Journal of Personality and Social Psychology, 54, 1063-1070. 


\section{Author Note}

Special thanks to Director Maria Nélida de Juano, teachers and staff at the Program Internacional Facultad de Derecho, Universidad Nacional de Rosario. Particularly thanks to the Spanish Conversation class teachers Sabina Chiaverano, Gabriele Alcaniz, Soledad Aramburu, Gisel Panza, Karina Ilopart who allowed me to collect data in their classes; and special recognition to María Fernanda González for her good efforts at collecting the end of term questionnaires. 


\section{Victor Savicki}

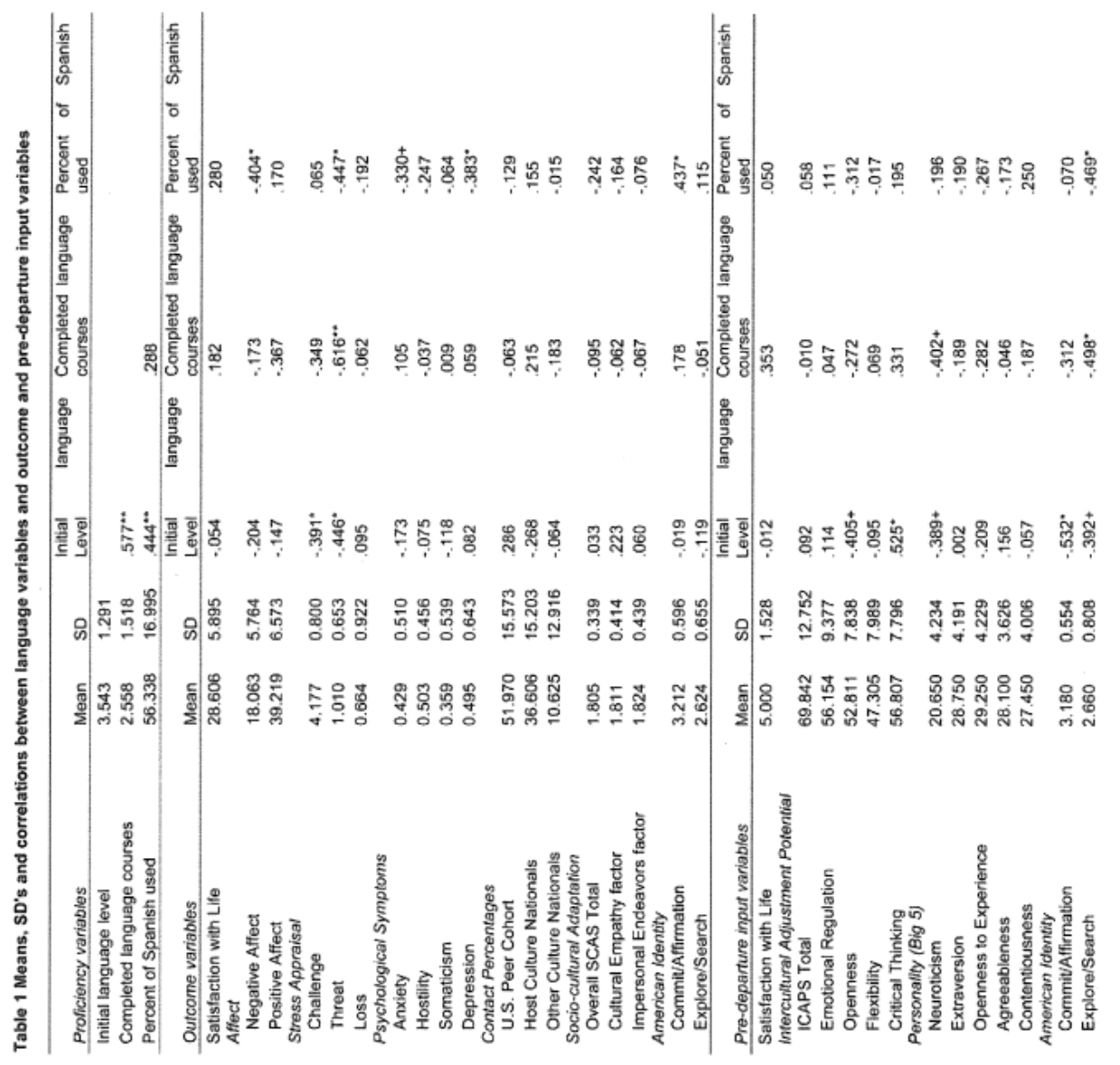




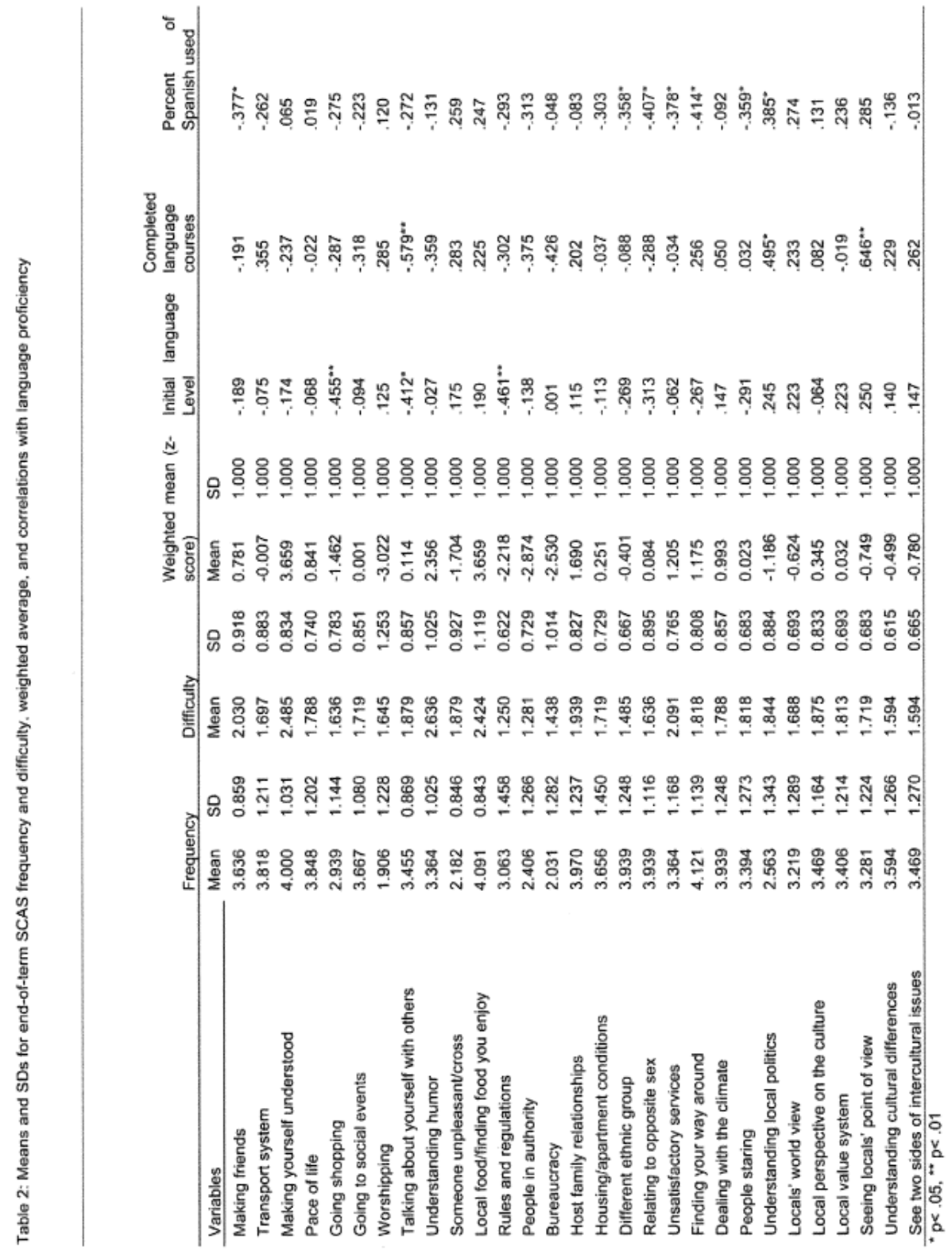




\section{Victor Savicki}

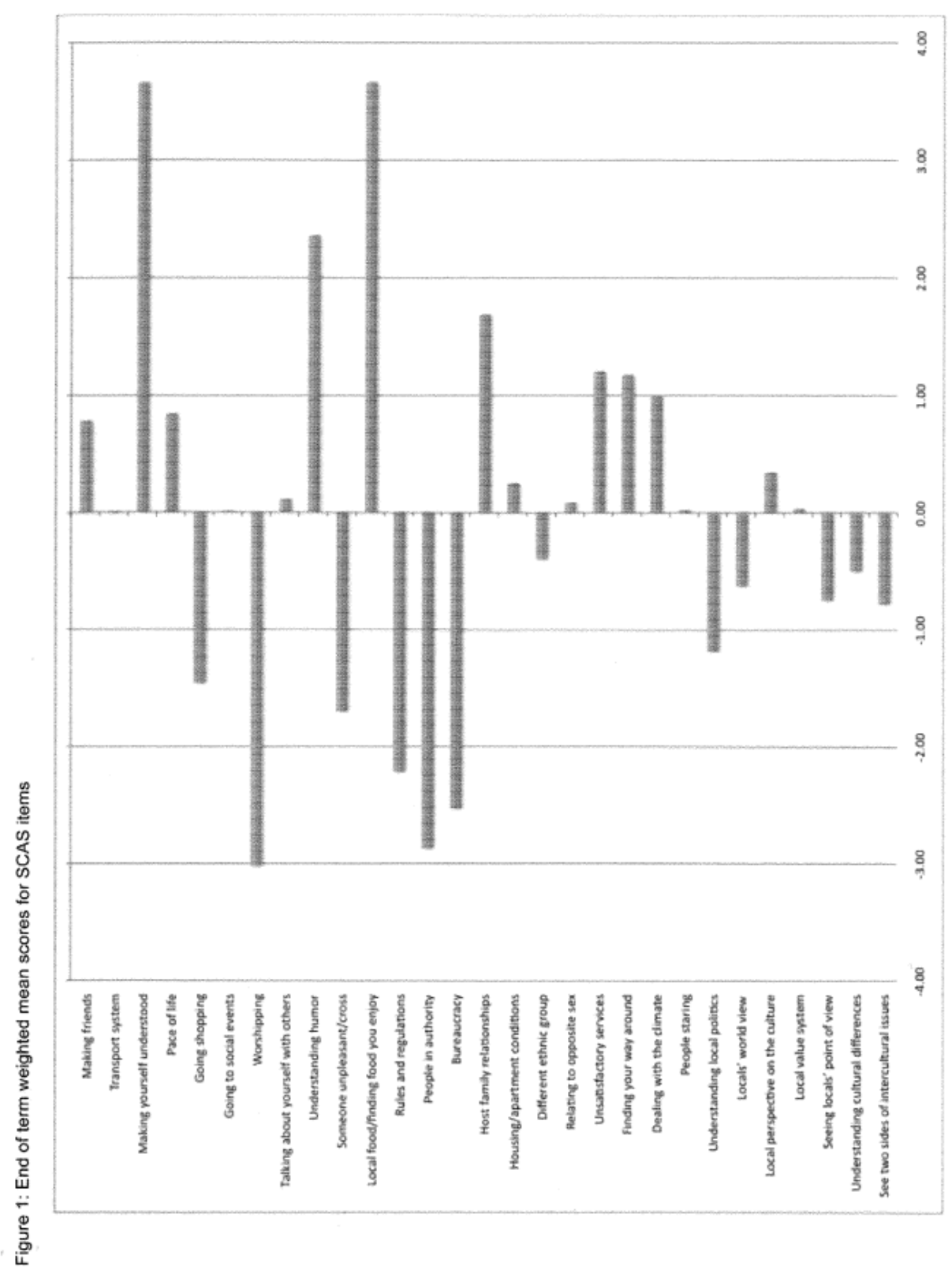

